\title{
Erratum to: Field-effect passivation on silicon nanowire solar cells
}

Anna Dalmau Mallorquí ${ }^{1}$, Esther Alarcón-Lladó ${ }^{1}$, Ignasi Canales Mundet ${ }^{1}$, Amirreza Kiani ${ }^{1}$, Bénédicte Demaurex ${ }^{2}$, Stefaan De Wolf ${ }^{2}$, Andreas Menzel ${ }^{3}$, Margit Zacharias ${ }^{3}$, and Anna Fontcuberta i Morral ${ }^{1}(\varangle)$

' Laboratoire des Matériaux Semiconducteurs, École Polytechnique Fédérale de Lausanne, 1015 Lausanne, Switzerland

2 Photovoltaics and Thin Film Electronics Laboratory, Institute of Microengineering (IMT), École Polytechnique Fédérale de Lausanne, 2000 Neuchâtel, Switzerland

${ }^{3}$ Nanotechnology, Institute of Microsystems Engineering (IMTEK), Albert-Ludwigs-University, 79110 Freiburg, Germany

(C) Tsinghua University Press and Springer-Verlag Berlin Heidelberg 2016

\section{Erratum to}

Nano Research 2015, 8(2): 673-681

DOI 10.1007/s12274-014-0551-7

The name of the author "Margit Zacharias" in the original version of this article was unfortunately wrongly written on page 673 and the first page of ESM, instead of

Anna Dalmau Mallorquí1, Esther Alarcón-Lladó1, Ignasi Canales Mundet ${ }^{1}$, Amirreza Kiani ${ }^{1}$, Bénédicte Demaurex², Stefaan De Wolf², Andreas Menzel ${ }^{3}$, Margrit Zacharias ${ }^{3}$, and Anna Fontcuberta i Morral ${ }^{1}(\varangle)$.

It should read

Anna Dalmau Mallorquí1, Esther Alarcón-Lladó ${ }^{1}$, Ignasi Canales Mundet ${ }^{1}$, Amirreza Kiani ${ }^{1}$, Bénédicte Demaurex², Stefaan De Wolf², Andreas Menzel ${ }^{3}$, Margit Zacharias ${ }^{3}$, and Anna Fontcuberta i $\operatorname{Morral}^{1}(\varangle)$.

The online version of the original article can be found at http://dx.doi.org/10.1007/s12274-014-0551-7.

Address correspondence to anna.fontcuberta-morral@epfl.ch 